\title{
BMJ Open Randomised clinical trial research within Aboriginal and Torres Strait Islander primary health services: a qualitative study
}

\author{
Penelope Abbott (D) , ${ }^{1}$ Deborah Askew, ${ }^{2}$ Chelsea Watego, ${ }^{3}$ Wendy CY Hu, ${ }^{1}$ \\ Letitia Campbell, ${ }^{4}$ Claudette Tyson, ${ }^{5}$ Robyn Walsh, ${ }^{1}$ Sylvia Hussey, ${ }^{6}$ Kerrie Doyle, ${ }^{1}$ \\ Hasantha Gunasekera, ${ }^{7}$ Amanda Jane Leach (1) , ${ }^{8}$ Tim Usherwood, ${ }^{7}$ \\ Jessica Armstrong-Kearns, ${ }^{1}$ Jennifer Reath (D) ${ }^{1}$
}

To cite: Abbott P, Askew D, Watego C, et al. Randomised clinical trial research within Aboriginal and Torres Strait Islander primary health services: a qualitative study. BMJ Open 2021;11:e050839. doi:10.1136/ bmjopen-2021-050839

- Prepublication history for this paper is available online. To view these files, please visit the journal online (http://dx.doi. org/10.1136/bmjopen-2021 050839).

Received 03 March 2021 Accepted 15 November 2021

Check for updates

(C) Author(s) (or their employer(s)) 2021. Re-use permitted under CC BY-NC. No commercial re-use. See rights and permissions. Published by BMJ.

For numbered affiliations see end of article.

Correspondence to

Penelope Abbott;

p.abbott@westernsydney.edu.au

\section{ABSTRACT}

Objective To better understand how to undertake valuable, ethical and sustainable randomised controlled clinical trial (RCT) research within Aboriginal and Torres Strait Islander primary health services.

Design In a qualitative approach, we utilised data collected between 2013 and 2020 during the planning and implementation of two RCTs. The data comprised agreed records of research meetings, and semistructured interviews with clinical trial stakeholders. The stakeholders were parents/carers of child participants, and site-based research officers, healthcare providers and community advisory groups. Our thematic analysis was informed by constructivist grounded theory.

Setting The RCTs investigated the management of otitis media in Aboriginal and Torres Strait Islander children, with the first RCT commencing recruitment in 2014 and the second in 2017. They took place in Aboriginal Medical Services (AMSs), large primary health services for Aboriginal and Torres Strait Islander people, based in urban and regional communities across two Australian states and one territory.

Results We analysed data from 56 meetings and 67 interviews, generating themes on making research valuable and undertaking ethical and sustainable RCTs. Aboriginal and Torres Strait Islander leadership, and support of AMSs in their service delivery function were critical. The broad benefits of the trials were considered important to sustainability, including workforce development, enhanced ear healthcare and multidirectional research capacity building. Participants emphasised the long-term responsibility of research teams to deliver benefits to AMSs and communities regardless of RCT outcomes, and to focus on relationships, reciprocity and creating positive experiences of research.

Conclusion We identify principles and strategies to assist in undertaking ethical and sustainable RCTs within Aboriginal and Torres Strait Islander primary health services. Maintaining relationships with AMSs and focusing on mutual workforce development and capacity building creates opportunities for long-term benefits so that health research and RCTs work for Aboriginal and Torres Strait Islander peoples, services, communities and researchers.
Strengths and limitations of this study

- This qualitative study was conducted over a 6-year period, alongside the planning and implementation of two RCTs undertaken in Aboriginal and Torres Strait Islander primary health services.

- Multiple stakeholder perspectives have informed our findings.

- Our research team allowed a mix of expertise to inform analysis, including that of Aboriginal Medical Services-based research officers.

- Our research team's involvement in the RCTs as well as in this qualitative study may have led to a positive bias, or to overlooking findings that would have appeared novel to an external researcher.

Trial registration number ACTRN12613001068752 (Preresults); ACTRN12617001652369 (Pre-results).

\section{INTRODUCTION}

Randomised controlled trials (RCTs) generate high level evidence, but are resource intensive. Barriers to conducting RCTs in primary care settings include physician concerns that the burdens to patients and providers outweigh the benefits, such as through negative effects on clinic workflow. ${ }^{1}$ Lack of research infrastructure, an underresourced workforce, and the Australian fee for service funding model, contribute to the challenge. ${ }^{2}$ Yet the evidence generated in primary care settings may be more translatable across diverse populations, contexts and priority conditions than evidence from tertiary settings.

Relatively few clinical trials have been undertaken in Aboriginal and Torres Strait Islander primary health services. Aboriginal and Torres Strait Islander peoples are the First Nations peoples of Australia and 
represent two distinct cultural groups, within which there is great diversity as seen by the over 250 different language groups across Australia. ${ }^{3}$ They may choose to access primary care through Aboriginal Medical Services (AMSs), which aim to provide holistic health and wellbeing services for Aboriginal and Torres Strait Islander individuals and their families. AMSs are mostly boardgoverned community-controlled organisations. Large AMSs may provide a wide range of services including access to medical and allied health specialities and social support services. ${ }^{4}$

The need for research evidence supporting the health and well-being of Aboriginal and Torres Strait Islander people is clear. High quality and ethical research with Aboriginal and Torres Strait Islander communities requires coming together with commitment, knowledge, acceptance and trust. ${ }^{5}$ There has been a history of poor research through failure to listen to communities and an emphasis on observational and deficit-focused research. ${ }^{6}$ Ethical guidelines for researchers and stakeholders identify six core values which must be upheld in Aboriginal and Torres Strait Islander research: spirit and integrity, cultural continuity, equity, reciprocity, respect and responsibility. ${ }^{7}$ Guidelines on how to operationalise these values in Indigenous research may assist. ${ }^{8}$ Careful reflection on these values and how to enact them may be even more important in designing and implementing RCTs, given the relatively rigid and predefined research processes involved.

We have been undertaking two RCTs into the management of acute and chronic otitis media since 2013, in a partnership between multiple AMSs and academic institutions. ${ }^{9}$ Otitis media is inflammation or infection of the middle ear space. It can be a complex health problem which results in hearing loss and negative effects on education, employment and wellbeing. Aboriginal and Torres Strait Islander people are disproportionately affected by otitis media and its sequelae. ${ }^{10}$

In this qualitative study, our goal was to better understand how to undertake ethical, sustainable and valuable clinical trial research within Aboriginal and Torres Strait Islander primary health services.

\section{METHODS}

This study was integrated with the WATCH ${ }^{9}$ and INFLATE trials, and began during the WATCH planning phase in October 2013 and continued alongside both RCTs until April 2020.

\section{Setting}

At the point of analysis in our qualitative study, WATCH (commenced in 2014) and INFLATE (commenced in 2017) had been running concurrently in AMSs in urban and regional areas across two states and one territory of Australia. Recruitment to both trials continued. Twelve AMSs had been involved in one or both trials and six AMSs were current members of the network. Some AMSs were part of the research from its beginnings, while others joined later. Six left the network between 2013 and 2020, after periods of time ranging from 2 months to 3 years. Eleven AMSs were Aboriginal community-controlled health organisations, and one was a government-run service. The duration of involvement by individual AMSs in the RCTs ranged from 6 months to over 6 years at April 2020.

Each AMS was funded to employ a research officer (RO) supported by university-based research staff. Choices related to $\mathrm{RO}$ recruitment were made by individual AMSs. Most AMSs employed ROs from their local community and 14 of 16 ROs were Aboriginal and Torres Strait Islander people. Multiple other AMS staff were involved in the RCTs, including an AMS-nominated Associate Investigator, and healthcare providers, primarily general practitioners, practice nurses and audiologists. Each AMS was offered funding for a community advisory group.

Western Sydney University was the lead academic institution, with six other academic institutions involved. WATCH and INFLATE had shared governance. The steering committee comprised investigators, AMSnominated representatives and an Aboriginal and Torres Strait Islander community health sector representative. The steering committee met remotely five times a year, and a large face-to-face meeting of the full research team was convened every $6-12$ months, with invitees including the steering committee, Associate Investigators, ROs and university-based research staff.

\section{The background to WATCH and INFLATE}

The WATCH trial commenced with discussion between clinician-researchers and management at a partner AMS concerning the burden of childhood ear infections and uncertainties as to applicability of clinical guidelines to urban Aboriginal and Torres Strait Islander children. After 3 years of the WATCH trial, more recruitment was needed and AMSs and ROs were in favour of an ongoing and more stable role in otitis media research. Research priorities were discussed and an application for INFLATE was subsequently successful.

\section{Qualitative study team}

Our team had different roles within the trials (nine Investigators, two university-based ROs and three ROs), and were a mix of experienced and novice qualitative and clinical trial researchers. Five were Aboriginal and Torres Strait Islander people.

\section{Data sources and collection}

The data comprised agreed records (minutes) of the steering committee, full research team and community advisory group meetings and semistructured interviews with clinical trial stakeholders. The stakeholders were parents/carers of child participants, ROs, AMS healthcare providers and community advisory group members. 
Five team members conducted interviews face-to-face or by telephone between December 2015 and April 2020. The interviewers did not have direct reporting relationships with participants. Interview topics included experiences of the WATCH and INFLATE trials, and views on research and RCTs in this context. Participant-led content was encouraged.

We purposively selected parents/carers with a range of trial experiences, including those who had completed, withdrawn or declined trial participation. Healthcare providers were purposively selected for a range of professional and trial-related roles and AMS locations. We interviewed consenting ROs at least once, with those who worked in the trials for a number of years participating in two or three interviews over time. Two ROs who worked in the trials for 6 months declined an interview with no reason given. We advised ROs their data would be deidentified, but could still be recognisable to the qualitative research team, and they had the opportunity to revise their transcripts. All interviewees were happy to have their interview audio-recorded, transcribed and deidentified, but notes were made for one RO interview after audio-recorder malfunction. Meeting records were deidentified prior to analysis.

\section{Data analysis}

We combined interview transcripts and minutes into one data set, handled using NVivo V.12 (QSR). We tagged data according to participant or meeting characteristics and timing of interview or meeting. We undertook reflexive thematic analysis, ${ }^{11}$ informed by constructivist grounded theory. ${ }^{12}$ This recognised the need for reflection on the effect of the researchers and research process on the data and analysis, given the research context, our varied backgrounds and our insider roles within the WATCH and INFLATE trials. Initial coding of the data, followed by iterative focused coding, memo writing and team discussions, were used to generate themes. Six team members contributed to initial coding, including concurrent coding of one third of the data. Analysis proceeded through ongoing discussion and refinement of themes.

\section{Patient and public involvement statement}

Patients at the AMSs were involved in the design of this study, providing advice via community advisory groups and to AMS-based ROs, as well as providing data in the form of interviews and minutes of advisory group meetings. This paper will be disseminated to all participating AMSs via email, and a lay summary in verbal and poster form will be disseminated to the communities, including via waiting rooms, social media and community events.

\section{RESULTS}

Two group and 65 individual interviews were undertaken between 2015 and 2020 (table 1), with a mean duration of 30 (range 10-77) min. Minutes from 56 meetings-steering committee $(n=37)$, full research team $(n=10)$ and AMS community advisory groups $(n=9)-$ were included in the data set. We generated two key

Table 1 Interview participants

\begin{tabular}{|c|c|c|c|}
\hline Participant group & Number of interviews & Details & Representing sites \\
\hline Parents/carers & 20 individual interviews & $\begin{array}{l}\text { Completed the WATCH study }=10 \\
\text { Withdrew from WATCH=2 } \\
\text { Declined participation in WATCH=2 } \\
\text { Completed INFLATE }=6 \\
\text { Unable to continue INFLATE due to } \\
\text { coronavirus pandemic }=1 \\
18 \text { female carers, } 2 \text { male carers } \\
\text { (one carer had a child in INFLATE and a } \\
\text { different child in WATCH) }\end{array}$ & 5 AMSs \\
\hline AMS research officers & 21 individual interviews & $\begin{array}{l}\text { Individual ROs }=14 \\
-3 \text { ROs did } 2 \text { interviews } \\
-2 \text { ROs did } 3 \text { interviews }\end{array}$ & 9 AMSs \\
\hline AMS healthcare providers & $\begin{array}{l}25 \text { individual interviews } \\
1 \text { pair interview }\end{array}$ & $\begin{array}{l}\text { General practitioners=9 } \\
2 \text { GPs did } 2 \text { interviews } \\
\text { Nurses: } 7 \\
\text { GP registrars: } 6 \\
\text { Practice manager: } 1 \\
\text { Audiologists: } 2\end{array}$ & $7 \mathrm{AMSs}$ \\
\hline AMS advisory group members & $\begin{array}{l}1 \text { individual interview } \\
1 \text { pair interview }\end{array}$ & $\begin{array}{l}\text { All were community members, one was a } \\
\text { patient of the service and two were non- } \\
\text { clinical AMS staff members }\end{array}$ & 1 AMS \\
\hline
\end{tabular}

AMS, Aboriginal Medical Services; GPs, general practitioners; RO, research officers. 
themes: what makes research valuable and undertaking ethical and sustainable RCTs in AMSs.

\section{Making research valuable}

The essential value in all types of research was perceived to be the potential for improvement in community health and well-being. Intervention research, such as WATCH and INFLATE, was seen as a good way to improve health outcomes and generate positive evidence for communities. This was preferred over descriptive research which was associated with a deficit narrative.

I'd rather see more outcomes and positive publicity, than saying how many problems Aboriginal communities have got... instead of trying to get all the numbers of what's wrong, we need to know that strategies are working to get them better. (RO 4, 2016)

The research topic was important, and research related to children, youth and mental health were seen as priorities. Parents/carers and community members found ear health in childhood relatable, which aided acceptability of WATCH and INFLATE.

I'd do anything to help, especially when we're trying to help fix these little people that get these horrible ear infections. (Parent/carer 8, 2017)

Three years ago I was sceptical. I was like, "This is just another thing to spend money on Aboriginal Medical Services, what are we going to research now", ...but now what (RO) has done it's a very valued thing... Very beneficial for the mob, you know. Previous to that I didn't know that ear disease was such a big thing. (AMS Community advisory group, 2019)

Undertaking research in an AMS was seen to enhance the value and trustworthiness of the research, including because community oversight would ensure research was done according to community and cultural protocols.

From what I see, I think that people that would like research done, like it to come here because they know it'll be done properly, the results will be fair. (AMS nurse 16, 2017)

Clinical trials were not considered more problematic than other research. Some parents/carers and AMS staff believed the defined research question could make the research relatively easy for participants to understand. However, the paperwork and time required for research processes did surprise many healthcare providers, ROs and parents/carers, most of whom felt it was manageable, although some found it onerous.

Number one, (RCTs are) hard work, but two, I think, people actually they understand it's research, sometimes they - it's the most obvious, sort of, research, we're going directly for a clinical question, $\ldots$ and the mums or parents who consent, they understand what's going on if you explain it right. (AMS GP 5, 2016)
I wouldn't feel good if I just pulled out, but in saying that, I guess I would second guess redoing it, having to do the amount of paperwork involved (Parent/ carer 2, 2015)

\section{Undertaking ethical and sustainable RCTs}

Important factors in making RCTs in Aboriginal and Torres Strait Islander primary care services ethical and sustainable related to Aboriginal and Torres Strait Islander leadership, support for AMS service delivery, maximising research benefits despite recruitment challenges, maintaining relationships, workforce development and multidirectional capacity building.

\section{Aboriginal and Torres Strait Islander leadership}

There was emphatic recognition of the importance of leadership from Aboriginal and Torres Strait Islander researchers and community members. They were seen to provide scientific, clinical, contextual and cultural expertise, and assist greatly in building the research capabilities of non-Indigenous researchers. The Aboriginal investigators were considered role models within the research team. When a senior investigator resigned due to competing priorities, their expertise was greatly missed and engagement with other Aboriginal academics was prioritised.

(RO) has not experienced feeling culturally unsafe within the wider network at any team events or meetings. However, she perceives there is no longer adequate Aboriginal leadership in the trials, due to the big gap after (Investigator) left the team. (Notes from unrecorded interview with RO 9, 2019)

At the start of the WATCH trial, the Aboriginal investigators and the AMS community advisory groups were seen to provide this leadership. However, as the trials continued, longer-term ROs increasingly took on leadership roles as they gained experience and confidence. Their expertise was more widely acknowledged and trusted by themselves, AMS staff and the research team. Several ROs noted that they were increasingly confident in team discussions and in representing the research externally.

I said to (research staff), 'I'm not going to do any public speaking okay'. She said, 'You don't have to all right. We would love you to but you can say no'. I've done four since I've been in this job so I am so proud of myself... I'm a research officer, and I'm a leader, and I'm the one responsible for this role. I think I've learnt heaps and I know it. That's why I can stand up there and voice my opinion and talk. (RO 10, 2017)

In AMSs, parents/carers and healthcare providers relied on ROs for advice and running the trials, and ROs were able to raise the profile of research and could be seen as representatives of AMS-based research.

(RO) is a real success story. To be an employee of the year doing a research project that is affecting the 
community, affecting little kids and staff nominating, that's amazing. (AMS Community advisory group, 2019)

Within the research team, ROs increasingly informed research decisions and were community advocates. Longstanding ROs joined the steering committee, providing additional Aboriginal and Torres Strait Islander leadership at a governance level, even though this could be initially challenging as ROs built up confidence. A nonhierarchical team approach was cultivated.

(RO) feels a responsibility to keep driving issues important to Aboriginal people, and this is the main reason she took on the steering committee role... she feels that she can keep an eye out and do her best to provide an Indigenous voice. However, it can be hard to speak out, and to feel confident. (Notes from unrecorded interview with RO 9, 2019)

It feels like everyone's on the same, you know - on the same sort of level, even though there's so many experienced people on the team. So it's a little bit different in other environments we go to... they're experts in their field and very well educated. And when you go to the team meets and can talk with everyone, you feel as if you're on the same field. (RO 3, 2016)

\section{Supporting AMSs key business in service delivery}

The importance of minimising the research impact on clinical service delivery was emphasised in minutes and in interviews with AMS staff and parents/carers. Compensating AMSs financially for healthcare provider time spent on research was needed given the fee for service primary care funding model is based on direct patient care. Even though AMSs were financially recompensed in WATCH and INFLATE, healthcare providers experienced time pressure from queuing patients. Employing ROs to manage RCT processes within AMSs decreased service disruption, particularly when ROs were full time.

What would normally be anywhere from five to 15 or 20-minute consultation, depending on the patient, the family and how well they were, suddenly became an hour-long process that was extremely disruptive to the day. (AMS GP 10, 2016)

The RCTs were strongly identified to enhance ear health service delivery at AMSs and benefit patients through improving understanding, diagnosis and management of otitis media. Apart from study-related monitoring of ear health, this occurred through ROs checking in with parents/carers of participants at study visits and other times, providing support and health education, and acting as care navigators. They facilitated access to healthcare providers such as audiologists and otolaryngologists. Benefits went beyond the children participating in the trials, including healthcare provider and community education, ear screening at AMSs, community events and school visits and access to clinical equipment which could be used for all patients.
The money's not just sitting in a university somewhere, it's going to a clinic and on the ground support and so things like ear checks ... It allows the service to offer more to our patients as well, and continuity of care, so I can keep track of the kids with ear problems. (RO 8, 2018)

(RO) has been such a great help. And helps you to understand a lot more too. You can take what you learn from the program that they're in and obviously go home and help your relatives as well - your cousins, nieces and nephews when they have an ear issue... instead of them suffering with it, you can let them know to get to a doctor and make sure. (Parent/carer $16,2020)$

Finding physical space for ROs to do their work was a problem in most AMSs as they were already under space pressure for service delivery. This required flexibility by ROs and AMS staff, and sometimes substantial relationship work. Strategies seen as useful to address this included providing laptops and mobile phones so ROs could move as needed within the service, and offering trial participants home visits.

Lack of space has been difficult, has required (RO) to be flexible and determined to find somewhere from where she can operate despite barriers, she hopes she will have a more reliable space in the new clinic. She notes that other people in the service have been accommodating-letting her perch in their rooms, also to use the staff kitchen. (Full research team meeting 2019)

Patient care imperatives took precedence over research, and it was emphasised that researchers must understand this if they want to undertake clinical trials in AMSs.

Be aware how much impact in time that it would have on our clinic time. Because if you've got patients and you've got research, your patients are going to come first. Yeah, so they've come here, they're sick, there's something wrong, you've got to see them. (AMS nurse 16,2017 )

\section{Reflecting on research benefits amidst recruitment challenges}

Recruitment challenges and the need for additional funding to extend the trials due to slower than expected recruitment were frequently discussed in meetings. There was repeated assessment of trial processes and the broad circumstances within the research and the AMSs which affected recruitment. This could create tension, as ROs felt the pressure of slow recruitment. They expressed that they could feel blamed during group discussions, or could worry they were not performing well or their AMS was being negatively compared with others.

Recruitment is the biggest issue and sites have been sharing ways they can boost recruitment; some difficulties with equipment. ROs getting frustrated with being talked to about recruitment. We need to 
reinforce the positives not put them under pressure. (Steering committee, 2015)

There's no pressure from anybody else but myself, but there is pressure ... making sure that I'm really trying to screen... I don't want the one place like (AMS) to fail at it. (RO 14 2019)

One way the issue of slow recruitment was managed was through explicit reflection on the benefits of the trials in making a difference to ear health, and in building research skills and relationships with AMSs. These approaches were planned from inception and continually revisited, becoming increasingly important points of discussion as the trials lengthened.

The difficulty is that we are needing the research done and also need to contribute to the Aboriginal and Torres Strait Islander research paradigm. Advised that we need to think what are the things that we can provide: mentoring, clinical support, training. (Steering committee, 2013)

Discussion: what if we don't get recruits-how can we keep work going? ... we need to focus on what we can do to make a difference (Full research team meeting, 2018)

\section{Maintaining relationships with AMS research partners beyond the} trials

The main reasons for AMSs leaving the trials were difficulty in recruiting participants and AMS organisational changes. Meeting minutes demonstrated a focus on ensuring respectful relationships with departing AMSs and leaving the door open for future partnerships. This imperative was reinforced by ROs, who noted it was important AMSs and communities had a positive experience of research to enable future research, particularly given the history of poor research practice in communities.

The importance of leaving on good terms ... There is a fallacy around that Aboriginal communities do not like research-but they don't like badly done research. You want to leave the community ready to work with other researchers in the future, not leave them with a bad experience of research (Full research team meeting, 2019)

Another relational aspect considered important was recognising unique challenges for each AMS in implementing the RCTs and providing adequate establishment time and support to AMSs. Ultimately, a mutual decision could be reached for an AMS to withdraw. The substantial time spent in this process was seen to be respectful and trust-building, including in establishment of long-term relationships between the AMSs and research team. This time was also seen as justifiable by the research team and AMSs because of the clinical benefits of ear health assessments despite low recruitment to the RCTs.
(Investigator) noted the importance of what sites are doing in terms of screening patients even where only small number of patients have been recruited. (Full research team meeting, 2015)

(RO) emphasised the importance of the slow lead in to the trials at (AMS). Especially as she was not from that community she needed to listen and build up relationships and felt that took at least 3 months. 'I needed to establish the research path and who I am'. Feels she has done that in one clinic and now needs to do it in the other two. (Full research team meeting, 2019)

\section{Workforce development and multidirectional capacity building}

It was widely perceived that the trials enhanced AMS capacity and healthcare provider capabilities in ear health as well as in research. Despite being employed in a research role, in most AMSs, the ROs were also seen by patients and staff as embedded ear health workers, with tasks including teaching GPs how to use diagnostic equipment, fielding enquiries from parents/carers about ear health and supporting patient management. ROs embraced these added responsibilities, which were also encouraged by AMSs, with many offering ROs clinical educational opportunities such as audiometry training.

(RO) now enrolled in audiometry course. Has recognise credit, has to do five modules instead of 20 and reduced cost because of WATCH-INFLATE role. (RO) isn't just working on trial-does a lot of advocacy for patients. (RO) becomes the go to person. (Full research team meeting, 2019)

Involvement in the trials was considered to build AMS research experience, bringing future benefits to AMSs.

I think it would make a huge difference to (AMS) to have a culture of research because I think that's where they do want to go later. They would like to pick up some more research projects. But this is still very new to us so we're trying to find our feet. (RO 6 , 2016)

A goal of increasing the Aboriginal and Torres Strait Islander research workforce and a focus on $\mathrm{RO}$ research skills development was evident in the minutes. Strategies considered successful were regular training and networking during face to face meetings and workshops, mentoring, opportunities for ROs to contribute to substudies, authorship of research papers, conference presentations and an annual professional development allowance for ROs.

Capacity building within the trials was a standing item in meetings, and documentation under this item in early minutes related to $\mathrm{RO}$ mentoring and training opportunities. Although this remained a goal, there was increasing reflection that the term 'capacity building' had hierarchical and negative implications, and simplistic usage could contribute to a negative 
discourse suggesting AMSs and ROs lacked capacity and capabilities. Aboriginal investigators led the team to reflect on problematic uses of the term capacity building. Increasingly careful reflection in team meetings was minuted, emphasising that capacity building was multidirectional with all members of the team learning from each other and developing new knowledge and skills.

Capacity Building: Mentoring programs, keep this area well documented throughout trial, keep track of opportunities as they arise throughout trial. (Full research team meeting 2014)

Implications of the term 'Capacity Building' discussed. May be useful as long as (the team) recognises the bi-directionality of the term, being applied in a positive way. (Steering committee, 2017)

\section{DISCUSSION}

We have identified key principles and useful strategies which can assist in undertaking valuable, ethical and sustainable clinical trial research within Aboriginal and Torres Strait Islander primary health services. The collection of interview data and meeting records over several years alongside the planning and implementation of the RCTs is a strength of our research, allowing focus on collaborative problem solving and evolving strategies. Our research was strengthened by a team of Aboriginal and Torres Strait Islander and non-Indigenous members, who brought varied perspectives including through different roles within the WATCH and INFLATE RCTs.

Principles which were critical to the RCTs' value and sustainability were Aboriginal and Torres Strait Islander leadership, supporting AMSs in service delivery, prioritising respectful long term relationships with AMSs and focusing on workforce development and multidirectional capacity building. These principles need to be considered from the inception of RCTs within Aboriginal and Torres Strait Islander primary health services, and are likely to have value in planning RCTs in diverse primary care settings.

Centring the RCTs on benefits to communities and partnering health services increased RCT sustainability at the same time as meeting the ethical requirements of research reciprocity. Reflecting on these benefits during trial implementation could balance tensions created by recruitment challenges. Such benefits may not be directly related to the research intervention being studied. Indirect benefits were highly valued in the WATCH and INFLATE trials, including workforce development and enhanced ear healthcare delivery, and needed to be part of research design to meet the expectations of AMSs.

Partnership is integral to ethical research in Aboriginal and Torres Strait Islander community settings. ${ }^{13}$ Our findings supported the need to prioritise relationships with AMS partners and their communities, and the importance of a long-term view of engagement. Key drivers of success identified in a systematic review of participation of Indigenous peoples in RCTs were relationship and partnership building, facilitated by active collaboration from the start of RCTs. ${ }^{14}$ Time is needed to set up a clinical trial network with Indigenous communities as each community is different and adequate time is needed to listen and learn. ${ }^{15}$

It is increasingly recognised that the concept of engagement in community-based RCTs must go beyond a transactional model which focuses on finding participants then disseminating results. ${ }^{16}$ Using community-based participatory research practices and principles may allow RCTs to be designed in a way that works for Indigenous communities and includes outcomes reflecting community concepts of success. ${ }^{17}$ Our research supports the need for participatory and long-term partnerships, with aspirations beyond a single research question. Gaps in research funding due to short funding cycles can make this difficult, requiring commitment from researchers and funding bodies.

A relationship-based approach was also essential within the WATCH-INFLATE research team. Strategies which we found to be effective were governance structures and frequent networking opportunities which sought to minimise hierarchical relationships, and ongoing professional development opportunities for ROs. The limited literature on the role of AMSbased ROs in RCTs suggests ROs experience challenges related to strongly felt responsibility to communities, and balancing service and research roles. ${ }^{18} 19$ Our research adds new insights into the central role of ROs as AMS-based RCT research staff, and the ways the RO role developed and was supported over time. They provided leadership as experts in trial implementation as well as 'insider experience ${ }^{, 20}$ given their multiple roles as community members, AMS staff and researchers. It was important that the research team recognised and supported this expertise. The ROs could feel responsible both for successful recruitment at their sites and for ensuring research was led in an ethical and collaborative way. While experiencing this as pressure at times, they were nevertheless able to manage these sometimes competing goals and become integrated representatives of research within AMSs and communities, particularly those ROs who worked for longer within the RCTs.

Our understandings of workforce development and multidirectional capacity building deepened as the trials progressed. Mutual learning and teaching is a strength-based approach to health research capacity building in the Aboriginal and Torres Strait Islander community context. ${ }^{21}$ Development of the Aboriginal and Torres Strait Islander primary care research workforce is important. However, researchers must recognise the community's capabilities and roles in determining what workforce is needed and how it should be developed. ${ }^{22}$ In supporting ROs' individual professional development aspirations within WATCH and INFLATE, we needed to recognise that this did not always include a 
traditional research career pathway, and it was important to also support the service-related roles of ROs. Meeting the self-determined needs of communities when undertaking research is integral to the ethical principle of reciprocity within Aboriginal and Torres Strait Islander health research, so that people and communities are able to define the benefits of research according to their own values and priorities. ${ }^{7}$ Our qualitative research provides evidence that an increased culture of research as well as improved healthcare delivery in AMSs could be an outcome of a RCT.

\section{CONCLUSION}

Clinical trials in Aboriginal and Torres Strait islander primary health services must be centred on ethical principles and relationships if they are to be valuable and sustainable. Health care and other indirect benefits which are created alongside research can help sustain commitment during even lengthy RCTs. Maintaining relationships with AMSs over time and considering multidirectional capacity building creates opportunities for health research and RCTs to work for Aboriginal and Torres Strait Islander peoples, services and communities.

\section{Author affiliations}

${ }^{1}$ School of Medicine, Western Sydney University, Campbelltown, New South Wales, Australia

${ }^{2}$ Primary Care Clinical Unit, University of Queensland, Brisbane, Queensland, Australia

${ }^{3}$ School of Public Health and Social Work, Queensland University of Technology, Brisbane, Queensland, Australia

${ }^{4}$ Kalwun Development Corporation, Gold Coast, Queensland, Australia

${ }^{5}$ Southern Queensland Centre of Excellence in Aboriginal and Torres Strait Islander Primary Health Care, Brisbane, Queensland, Australia

${ }^{6}$ Townsville Aboriginal and Islander Health Service, Townsville, Queensland, Australia ${ }^{7}$ University of Sydney, Sydney, New South Wales, Australia

${ }^{8}$ Child Health Division, Menzies School of Health Research, Darwin, Northern Territory, Australia

\section{Twitter Kerrie Doyle @auntykerrie2017 and Amanda Jane Leach @cre_ichear}

Acknowledgements We acknowledge our AMS partners in this research, both the health services and the communities they serve, including the Institute for Urban Indigenous Health, Kalwun Development Corporation, Southern Queensland Centre of Excellence in Aboriginal and Torres Strait Islander Primary Healthcare, Tharawal Aboriginal Corporation, Townsville Aboriginal and Islanders Health Service, Winnunga Nimmityjah Aboriginal Health Service and Yerin Eleanor Duncan Aboriginal Health Centre. We also acknowledge the broad research team of WATCH and INFLATE.

Contributors PA, JR, WH, DA, CB, HG, TU and AJL conceived and designed this research. $\mathrm{PA}, \mathrm{DA}, \mathrm{CB}, \mathrm{WH}, \mathrm{LC}$ and $\mathrm{RW}$ collected the data, and the qualitative analysis team was PA, JR, WH, DA, CB, LC, CT, SH, RW, KD and JA-K. PA led the writing of the manuscript and all authors contributed to and approved the final version. PA accepts full responsibility for the finished work and the conduct of the study, had access to the data, and controlled the decision to publish.

Funding This work was supported by the Australian Government National Health and Medical Research Council grant numbers GTN1046266 and GTN1120317.

Competing interests None declared.

Patient and public involvement Patients and/or the public were involved in the design, or conduct, or reporting or dissemination plans of this research. Refer to the Methods section for further details.

Patient consent for publication Not required.
Ethics approval This study involves human participants and was approved by Aboriginal Health \& Medical Research Council Ethics Committee, 13-2074/13 and 17-1286. Participants gave informed consent to participate in the study before taking part.

Provenance and peer review Not commissioned; externally peer reviewed.

Data availability statement No data are available. Participants did not consent to data sharing prior to data collection.

Open access This is an open access article distributed in accordance with the Creative Commons Attribution Non Commercial (CC BY-NC 4.0) license, which permits others to distribute, remix, adapt, build upon this work non-commercially, and license their derivative works on different terms, provided the original work is properly cited, appropriate credit is given, any changes made indicated, and the use is non-commercial. See: http://creativecommons.org/licenses/by-nc/4.0/.

\section{ORCID iDs}

Penelope Abbott http://orcid.org/0000-0003-4865-4823

Amanda Jane Leach http://orcid.org/0000-0002-4638-8392

Jennifer Reath http://orcid.org/0000-0002-0676-4402

\section{REFERENCES}

1 Taft $\mathrm{T}$, Weir $\mathrm{C}$, Kramer $\mathrm{H}$, et al. Primary care perspectives on implementation of clinical trial recruitment. J Clin Trans/ Sci 2020;4:61-8.

2 Liu H, Massi L, Eades A-M, et al. Implementing Kanyini GAP, a pragmatic randomised controlled trial in Australia: findings from a qualitative study. Trials 2015;16:425.

3 Australian Institute of Aboriginal and Torres Strait Islander Studies. Indigenous Australians: Aboriginal and Torres Strait Islander people Canberra, Australian Capital Territory, 2020. Available: https://aiatsis. gov.au/explore/articles/indigenous-australians-aboriginal-and-torresstrait-islander-people

4 Baba JT, Brolan CE, Hill PS. Aboriginal medical services cure more than illness: a qualitative study of how Indigenous services address the health impacts of discrimination in Brisbane communities. Int J Equity Health 2014;13:56.

5 Laycock A, Walker D, Harrison N, et al. Researching Indigenous health: a practical guide for researchers. Melbourne: The Lowitja Institute, 2011.

6 Thomas DP, Bainbridge R, Tsey K. Changing discourses in Aboriginal and Torres Strait Islander health research, 1914-2014. Med J Aust 2014;201:S15-18.

7 National Health and Medical Research Council. Ethical conduct in research with Aboriginal and Torres Strait Islander peoples and communities: guidelines for researchers and stakeholders. Canberra: Commonwealth of Australia, 2018.

8 Huria T, Palmer SC, Pitama S, et al. Consolidated criteria for strengthening reporting of health research involving Indigenous peoples: the consider statement. BMC Med Res Methodol 2019;19:173.

9 Abbott P, Gunasekera H, Leach AJ, et al. A multi-centre openlabel randomised non-inferiority trial comparing watchful waiting to antibiotic treatment for acute otitis media without perforation in low-risk urban Aboriginal and Torres Strait Islander children (the WATCH trial): study protocol for a randomised controlled trial. Trials 2016;17:119.

10 Kong K, Coates HLC. Natural history, definitions, risk factors and burden of otitis media. Med J Aust 2009;191:S39-43.

11 Braun V, Clarke V. Reflecting on reflexive thematic analysis. Qual Res Sport Exerc Health 2019;11:589-97.

12 Charmaz K. Constructing grounded theory. 2 edn. London: Sage, 2014.

13 Beks H, Binder MJ, Kourbelis C, et al. Geographical analysis of evaluated chronic disease programs for Aboriginal and Torres Strait Islander people in the Australian primary health care setting: a systematic scoping review. BMC Public Health 2019;19:1115.

14 Glover M, Kira A, Johnston V, et al. A systematic review of barriers and facilitators to participation in randomized controlled trials by Indigenous people from New Zealand, Australia, Canada and the United States. Glob Health Promot 2015;22:21-31.

15 Thomas LR, Rosa C, Forcehimes A, et al. Research partnerships between academic institutions and American Indian and Alaska native tribes and organizations: effective strategies and lessons learned in a multisite CTN study. Am J Drug Alcohol Abuse 2011;37:333-8.

16 Richard L, Piper D, Weavell W, et al. Advancing engagement methods for trials: the CORE study relational model of engagement for a stepped wedge cluster randomised controlled trial of 
experience-based co-design for people living with severe mental illnesses. Trials 2017;18:169.

17 Rink E, Knight K, Ellis C, et al. Using community-based participatory research to design, conduct, and evaluate randomized controlled trials with American Indian communities. Prev Chronic Dis 2020;17:E143.

18 Mentha RA, de Vries J, Simon PR, et al. Bringing our voices into the research world: lessons from the Kanyini vascular collaboration. Med J Aust 2012;197:55-6.

19 Liu H, Laba T-L, Massi L, et al. Facilitators and barriers to implementation of a pragmatic clinical trial in Aboriginal health services. Med J Aust 2015;203:24-7.
20 Poland F, Charlesworth G, Leung P, et al. Embedding patient and public involvement: managing tacit and explicit expectations. Health Expect 2019;22:1231-9.

21 McPhail-Bell K, Matthews V, Bainbridge R, et al. An "all teach, all learn" approach to research capacity strengthening in Indigenous primary health care continuous quality improvement. Front Public Health 2018;6.

22 Bond C, Brough M, Willis J, et al. Beyond the pipeline: a critique of the discourse surrounding the development of an Indigenous primary healthcare workforce in Australia. Aust J Prim Health 2019;25:389-94. 